\title{
Characterizing Awareness of Pre-Exposure Prophylaxis for HIV Prevention in Manila and Cebu, Philippines: Web-Based Survey of Filipino Cisgender Men Who Have Sex With Men
}

Arjee Restar ${ }^{1,2,3,4,5,6^{*}}$, MPH, PhD; Anthony Surace ${ }^{1 *}$, MA; Alexander Adia ${ }^{1,2}$, MPH; William Goedel $^{1}$, PhD; Adedotun Ogunbajo $^{1}$, MHS, MPH, PhD; Harry Jin ${ }^{1,4}$, MPH, PhD; Alberto Edeza ${ }^{1}$, PhD; Laufred Hernandez ${ }^{7}$, MMPM, MA; Susan Cu-Uvin ${ }^{1,2,8,9}$, MD; Don Operario ${ }^{1,2}, \mathrm{PhD}$

\footnotetext{
${ }^{1}$ Department of Behavioral and Social Sciences, Brown University School of Public Health, Providence, RI, United States

${ }^{2}$ Brown University Global Health Initiative, The Philippine Health Initiative for Research, Service, and Training, Providence, RI, United States

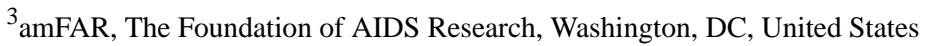

${ }^{4}$ Department of Epidemiology, Bloomberg School of Public Health, Johns Hopkins University, Baltimore, MD, United States

${ }^{5}$ Department of Epidemiology, School of Public Health, University of Washington, Seattle, WA, United States

${ }^{6}$ Department of Epidemiology, Brown University School of Public Health, Providence, RI, United States

${ }^{7}$ Department of Behavioral Sciences, University of Philippines in Manila, Manila, Philippines

${ }^{8}$ Providence-Boston Center for AIDS Research, Providence, RI, United States

${ }^{9}$ Department of Medicine, Miriam Hospital, Providence, RI, United States

*these authors contributed equally
}

Corresponding Author:

Arjee Restar, MPH, PhD

Department of Epidemiology

School of Public Health

University of Washington

3980 15th Ave NE

Seattle, WA, 98195

United States

Phone: 17046409953

Email: arjee restar@alumni.brown.edu

\section{Abstract}

Background: The Philippines is experiencing an HIV crisis and is considering implementing pre-exposure prophylaxis (PrEP) as a national public health strategy for HIV prevention for cisgender men who have sex with men (cis-MSM). However, critical information on the awareness of PrEP among cis-MSM is needed to roll out this public health initiative.

Objective: This study aims to assess PrEP awareness and related correlates (ie, sociodemographic variables, social factors, and health care access and use) among Filipino cis-MSM.

Methods: We conducted a web-based survey with Filipino cis-MSM (n=179) residing in the cities of Manila and Cebu, Philippines. Multivariable analysis procedures were performed to examine the factors associated with PrEP awareness.

Results: Our sample demonstrated high awareness (134/179, 74.9\%) and interest $(159 / 179,88.8 \%)$ in taking PrEP. The adjusted model showed that greater odds of PrEP awareness were associated with having a college education or higher versus a high school education or lower (adjusted odds ratio [aOR] 7.30, 95\% CI 1.01-52.47), earning between PHP 10,000 (US \$198.6) and PHP 20,000 (US \$397.2) versus <PHP 10,000 (US \$198.60; aOR 9.32, 95\% CI 1.41-6.22), having had a prior HIV test (aOR 6.06, 95\% CI 1.20-13.55), having high HIV knowledge (aOR 3.50, 95\% CI 1.11-10.98), and having friends who discussed PrEP (aOR $11.17,95 \%$ CI 2.73-14.5).

Conclusions: Our findings demonstrate that Filipino cis-MSM are aware of and interested in taking PrEP, but there is currently an unmet need for such biomedical HIV prevention technologies among this population. Incorporating PrEP education into routine HIV screening and leveraging cis-MSM social networks may be useful in optimizing potential PrEP implementation in the Philippines. 
(J Med Internet Res 2022;24(1):e24126) doi: 10.2196/24126

\section{KEYWORDS}

HIV prevention; PrEP; men who have sex with men; the Philippines

\section{Introduction}

\section{Background}

Globally, cisgender men (ie, individuals who identify their gender as men and are assigned the male sex at birth) who have sex with men (cis-MSM) remain highly vulnerable to HIV infection [1,2]. A meta-analysis found that the HIV prevalence among cis-MSM in the South and Southeast Asia region was $15 \%$ [2]. The Philippines, situated in Southeast Asia, is undergoing a major public health crisis as a result of the rapid increase in new HIV cases documented in the past decade. The number of people diagnosed with HIV in the Philippines has increased more than 4-fold, from 16,000 cases in 2010 to 68,000 in 2017 [3] and is concentrated among young, cis-MSM [4]. Of the 6011 new cases of HIV in 2014, $85 \%$ were attributed to male-to-male sexual contact with a median age at diagnosis of 28 years [4,5]. The major drivers of HIV infection among Filipino cis-MSM include receptive anal intercourse and sex under the influence of alcohol and other substances [5,6]. Use of HIV prevention services among this population remains low; in a survey of 531,000 cis-MSM in the Philippines, only half reported using condoms during their last sexual encounter [3], and HIV testing rates were lower among cis-MSM compared with those in China and Vietnam [7].

Pre-exposure prophylaxis (PrEP) is an evidence-based, effective biomedical HIV prevention strategy that significantly reduces HIV transmission risk [8]. Currently, PrEP is available as a daily oral pill (eg, Truvada, a combination of emtricitabine and tenofovir), which can reduce the risk of HIV infection by more than $90 \%$ when taken as prescribed $[9,10]$. To date, there is a single ongoing PrEP demonstration project among cis-MSM in the Philippines [11], and the Philippines Department of Health is considering approval of PrEP for public use. Examining levels of PrEP awareness and interest among cis-MSM in the Philippines will inform future rollout and scaling of PrEP programs, especially for vulnerable groups such as cis-MSM.

Awareness of and interest in taking PrEP are key determinants of successful initiation into the PrEP continuum of care $[12,13]$. PrEP awareness has been researched among American cis-MSM $[14,15]$, but analogous research in other parts of the world is scant. One of the few published reviews examining awareness and willingness to use PrEP among cis-MSM in low- and middle-income countries found low awareness (16.9\%-44.3\%) but high willingness to use PrEP for HIV prevention (53.3\%-74.8\%) [16]. Furthermore, a literature review of HIV research in the Philippines showed that there are only a few empirical studies on HIV prevention among cis-MSM, and none of these studies have explored PrEP [17]. Given the ongoing considerations to support implementation of PrEP in national guidelines in the Philippines, it is vital to assess the current level of PrEP awareness and interest among Filipino cis-MSM. Such data are critical for informing future PrEP implementation programs in the Philippines.

\section{Objective}

To date, no known quantitative study has explored awareness of PrEP among Filipino cis-MSM. There is a need for such research given the high vulnerability of Filipino cis-MSM to HIV infection and the heavy burden of HIV infection among this group. To this end, we carried out a web-based survey assessment to examine the relationship between PrEP awareness among Filipino cis-MSM and sociodemographic variables, social factors (eg, marginalization, cohesion, and participation), indicators of health care experiences and access to HIV services, and PrEP indicators.

\section{Methods}

\section{Participants and Procedures}

The data used in this study were obtained from Project \#ParaSaAtin, a web-based study that surveyed key populations (eg, cis-MSM) impacted by the HIV epidemic in the Philippines. Informed by epidemiological data, we focused on Manila or National Capital Region (NCR) and Cebu. Specifically, as identified in the Philippines HIV national surveillance report, these are the top geographical areas where HIV infection is concentrated in the Philippines [4]. The purpose of the survey was to examine the structural, social, and behavioral factors that impact the use of HIV/AIDS prevention services, such as PrEP, condoms, and HIV testing. This analysis focused specifically on PrEP awareness and willingness to take PrEP as outcomes of interest.

Between June 2018 and May 2019, we recruited participants by posting our study survey link on flyers and advertisements through web-based social media sites (eg, Facebook groups and Twitter) of community-based organizations that provided services to communities impacted by the HIV/AIDS epidemic in the Philippines. Participants who clicked on the survey completed a web-based written consent and screening process. Eligibility criteria for participants in this study included self-reporting that they (1) were $\geq 18$ years old, (2) identified as cis-MSM, (3) had condomless anal sex within the past year, (4) currently lived in Manila, NCR or Cebu, (5) demonstrated English comprehension (via a brief cognitive screening form), and (6) provided a web-based written consent to participate in the study. The brief cognitive screening form tested participants' capacity to understand English by asking participants a series of true or false questions based on the consent form. English is common in the Philippines (as it is one of the national languages) [18] but given that the survey was written in English, we wanted to ensure that the enrolled participants demonstrated sufficient language comprehension. To further ensure survey comprehension, we used the Flesch-Kincaid Reading Level Test [19] to design the survey such that it could be read by someone at the sixth grade level. The average range of time for participants to complete the survey was between 20 and 25 minutes. All participants received a PHP 300 (approximately 
US \$5.85) electronic prepaid mobile load card for their time and completion of the survey.

We also used best practices for conducting web-based survey questionnaires. This included having a series of standard web-based survey protective measures, such as (1) captcha box, which provides a web-based challenge-response test that eliminates robots from taking the survey $[20,21]$ and (2) unique IP address programming, which prevents the same participants from taking the survey multiple times by only allowing those with a unique IP address to take the survey [21,22]. Study procedures were deemed appropriate by all 3 local HIV/AIDS community-based organizations that were our local partners for this project and collaborated in the development and implementation of this survey. This study received ethical approval from the Brown University Human Research Protection Program Institutional Review Committee in Providence, Rhode Island.

\section{Measures}

We analyzed the correlates of PrEP awareness and interest using a series of questions on sociodemographic factors, social factors (eg, marginalization, cohesion, and participation), and indicators of health care experiences and access to HIV services among the participants.

\section{Sociodemographics}

We adapted sociodemographic items from the Philippines National Demographic and Health Survey [23]. With the exception of sexual identity, these items included age, current living location, education attainment, past year income, and religious affiliation.

\section{Social Marginalization, Cohesion, and Participation Variables}

We asked the participants about their social experiences, including marginalization, cohesion (ie, perception of mutual aid, trust, and support) [24], and participation in social events and activities.

For social marginalization, we asked if they had ever been homeless (yes or no), were currently unemployed (yes or no), and had engaged in sex work within the past 4 months (yes or no).

To measure social cohesion, we adapted a 9-item social cohesion scale [24] to specifically refer to cis-MSM communities (Cronbach $\alpha=.92$ ). Examples of these items are You can count on your cis-MSM friends if you need to talk about your problems and You can count on your cis-MSM friends to accompany you to the doctor or hospital. Each item had 5-level Likert response options, from strongly disagree (1) to strongly agree (5) and was summed (median 22; range 9-45). Similar to previous researchers' work on this scale [24-26], scores were dichotomized into low versus high levels of social cohesion at the median.

We asked about the engagement of the participants in general community events and activities (ie, general social participation), such as activities related to church, community, or cultural events as well as lesbian, gay, bisexual, and transgender
(LGBT)-specific activities (ie, LGBT-specific social participation), such as joining pageants, HIV advocacy groups, and local LGBT organizations. To assess gender- and LGBT-specific social participation, we adapted the social participation scale (Cronbach $\alpha=.76$ and .75, respectively) [25]. Keeping in-line with previous researchers [25,26], responses were either yes or no and were summed (median 1, range 0-4 for general social participation and median 3, range 0-5 for LGBT-specific social participation) and then dichotomized into low versus high levels of participation at the median.

\section{Health Care and HIV Service Indicators}

We assessed participants' health care experience by asking whether they had current health insurance (yes or no) and had ever been discriminated against because of sexual identity (yes or no). We used the health care accessibility scale by Haggerty et al [27] to measure our participants' health care accessibility (Cronbach $\alpha=.89$ ). Items included questions about how convenient their provider's office is with regard to office hours for appointments, duration of next open appointments, waiting time before appointments, traveling to and from the office, and ability to reach the provider when needed. Responses were scored (median 19, range 6-30) and dichotomized into poor or fair versus good or excellent health care accessibility at the median.

We assessed the experiences of access to HIV services, by asking the participants if they had ever had an HIV test. We also asked if they avoided seeking HIV services because of the cost of services, distance of travel to and from the health care facility, sexual identity, and lack of facility-level policy on LGBT antidiscrimination. To assess participant's HIV knowledge, we used the International AIDS Questionnaire (Cronbach $\alpha=.80$; median 40, range 23-74), and dichotomized the scores into high versus low HIV knowledge at the median [28].

\section{PrEP Indicators}

We adapted 3 items on PrEP awareness, interest, and discussion among friends from the study by Restar et al [29]. Specifically, we asked the participants whether they had heard of PrEP (yes or no). Regardless of their previous PrEP awareness, all participants then received a brief educational statement about PrEP [30]:
One way to fight HIV is called PrEP, which stands for pre - exposure prophylaxis. PrEP works by giving HIV - negative people HIV drugs to keep them from getting HIV. The following questions are about your thoughts and opinions of PrEP.

We then asked if they were interested in taking PrEP (not interested at all vs somewhat or very interested). We also asked the participants to rate how true the following statement is $-M y$ friends talk about PrEP — with response options as very or somewhat true versus not true at all. Participants who were not interested in PrEP were subsequently asked to enter their primary reason for being uninterested in PrEP. 


\section{Analysis}

Descriptive analyses were performed to determine proportions and chi-square tests and bivariable and multivariable logistic regression modeling were performed to determine associations among participants. Before running the regression procedures, we performed a sensitivity analysis to determine internal consistency for all of our scale variables (eg, health care accessibility, social cohesion and participation, and HIV knowledge). Multicollinearity tests using the standard procedure for assessing the variance inflation factor were performed to ensure that our independent variables were not collinear. Our results determined that collinearity was not present in our data (all variance inflation factors $<4.00$ ) [31]. Logistic regression procedures were performed to determine associations between PrEP awareness and sociodemographics, experiences of social marginalization, social cohesion and participation, health care, access to HIV services, and other PrEP indicators. We then descriptively examined the reasons for not having interest in PrEP. All analyses were performed using Stata standard edition version 15.1 (StataCorp LLC) [32]. Statistical significance was set at 2-sided $P<.05$.

\section{Results}

\section{Sample Characteristics}

A total of 179 cis-MSM completed the survey. Study sample characteristics are presented in (Table 1). 
Table 1. Study sample characteristics of Filipino cismen who have sex with men $(n=179)$.

\begin{tabular}{|c|c|c|c|}
\hline Characteristics & Total, n (\%) & $\operatorname{PrEP}^{\mathrm{a}}$-aware $(\mathrm{n}=134), \mathrm{n}(\%)$ & $P$ value $^{\mathrm{b}}$ \\
\hline \multicolumn{4}{|l|}{ Demographics } \\
\hline Age & & & .08 \\
\hline $18-24$ & $40(23)$ & $32(24.2)$ & \\
\hline $25-29$ & $59(33.9)$ & $45(34.1)$ & \\
\hline $30-34$ & $36(20.7)$ & $31(23.5)$ & \\
\hline$>35$ & $39(22.4)$ & $24(18.2)$ & \\
\hline Current living location & & & .52 \\
\hline Metro Manila or National Capital Region & $145(81)$ & $110(82.1)$ & \\
\hline Central Visayas & $34(19)$ & $24(17.9)$ & \\
\hline Highest educational attainment & & & .10 \\
\hline High school or lower & $23(12.9)$ & $13(9.7)$ & \\
\hline Some college & $34(19.1)$ & $26(19.6)$ & \\
\hline College or higher & $121(68)$ & $94(70.7)$ & \\
\hline Past year income & & & .27 \\
\hline$<$ PHP 10,000 (US \$198.60) & 25 (19.6) & $21(15.7)$ & \\
\hline PHP 10,000 (US \$198.60)-PHP 20,000 (US \$397.20) & $38(21.2)$ & $30(22.4)$ & \\
\hline PHP 20,000 (US \$397.20)-PHP 30,000 (US \$ 596.00) & $30(16.8)$ & $23(17.2)$ & \\
\hline >PHP 30,000 (US \$ 596.00) & $60(33.5)$ & $47(35)$ & \\
\hline No income in the past year & $16(8.9)$ & $13(9.7)$ & \\
\hline Religious affiliation & & & .14 \\
\hline Catholic & $144(80.4)$ & $105(78.4)$ & \\
\hline Non-Catholic (eg, Protestant, Christian) & $24(13.4)$ & $18(13.4)$ & \\
\hline Nonreligious & $11(6.2)$ & $11(8.2)$ & \\
\hline Sexual orientation & & & $.048^{\mathrm{c}, \mathrm{d}}$ \\
\hline Gay & $95(53)$ & $76(56.7)$ & \\
\hline Bisexual & $71(39.7)$ & $52(38.8)$ & \\
\hline Straight & $11(6.2)$ & $5(3.7)$ & \\
\hline Not listed & $2(1.1)$ & $1(0.8)$ & \\
\hline \multicolumn{4}{|l|}{ Social marginalization, cohesion, and participation } \\
\hline Ever homeless & & & .49 \\
\hline No & $158(88.3)$ & $117(87.3)$ & \\
\hline Yes & $21(11.7)$ & $17(12.7)$ & \\
\hline Recent ( $<4$ months) sex work engagement & & & .79 \\
\hline No & $153(85.5)$ & $114(85.1)$ & \\
\hline Yes & $26(14.5)$ & $20(14.9)$ & \\
\hline Currently unemployed & & & .18 \\
\hline No & $46(25.7)$ & $31(23.2)$ & \\
\hline Yes & $133(74.3)$ & $103(76.8)$ & \\
\hline Social cohesion & & & .24 \\
\hline Low & $82(45.8)$ & $58(43.3)$ & \\
\hline High & $97(54.2)$ & $76(56.7)$ & \\
\hline
\end{tabular}




\begin{tabular}{|c|c|c|c|}
\hline Characteristics & Total, n (\%) & $\operatorname{PrEP}^{\mathrm{a}}$-aware $(\mathrm{n}=134), \mathrm{n}(\%)$ & $P$ value ${ }^{\mathrm{b}}$ \\
\hline General social participation & & & .09 \\
\hline Low & $92(51.4)$ & $64(47.8)$ & \\
\hline High & 87 (48.6) & $70(52.2)$ & \\
\hline LGBT $^{\mathrm{e}}$-specific social participation & & & .002 \\
\hline Low & $109(60.9)$ & $73(54.5)$ & \\
\hline High & $70(39.1)$ & $61(45.5)$ & \\
\hline
\end{tabular}

HIV and other health care indicators

Current health insurance

$\begin{array}{ll}\text { No } & 88(49.2) \\ \text { Yes } & 91(50.8)\end{array}$

Health care discrimination because of sexual identity

$$
\text { No }
$$

Yes

Health care accessibility

$$
\begin{aligned}
& \text { Poor or fair } \\
& \text { Good or excellent }
\end{aligned}
$$

Ever had an HIV test

$$
\text { No }
$$$$
\text { Yes }
$$

Avoided HIV services because of the cost of services

$$
\begin{array}{ll}
\text { No } & 107(59.8) \\
\text { Yes } & 72(40.2)
\end{array}
$$

$153(85.5)$

$26(14.5)$

$93(52)$

$86(48)$

$$
\begin{aligned}
& 37(20.7) \\
& 142(79.3)
\end{aligned}
$$

Avoided HIV services because of distance of travel to and from the health care facility

$$
\text { No }
$$$$
107 \text { (59.8) }
$$$$
72(40.2)
$$

Yes

Avoided HIV services because of sexual identity
No
$129(72.1)$
Yes
50 (27.9)

Avoided HIV services because of lack of LGBT antidiscrimination policy
No
Yes
143 (79.9)
$36(20.1)$

HIV knowledge

$\begin{array}{ll}\text { Low } & 78(43.6) \\ \text { High } & 101(56.4)\end{array}$

PrEP-related indicators

PrEP discussion among friends

No
Yes

PrEP interest 


\begin{tabular}{|c|c|c|c|}
\hline Characteristics & Total, n (\%) & PrEP $^{\mathrm{a}}$-aware $(\mathrm{n}=134), \mathrm{n}(\%)$ & $P$ value ${ }^{\mathrm{b}}$ \\
\hline Very or somewhat & $159(88.8)$ & $118(88.1)$ & \\
\hline
\end{tabular}

${ }^{\mathrm{a} P r E P}$ : pre-exposure prophylaxis.

${ }^{\mathrm{b}}$ Chi-square test.

${ }^{\mathrm{c}}$ Fisher exact test. Comparison groups for both tests were pre-exposure prophylaxis-aware versus pre-exposure prophylaxis-unaware. ${ }^{\mathrm{d}} P<.05$.

${ }^{\mathrm{e}}$ LGBT: lesbian, gay, bisexual, and transgender.

Overall, most of the participants currently lived in Manila or NCR $(145 / 179,81 \%)$, had at least college education (121/179, $67.6 \%)$, self-identified as Catholic $(144 / 179,80.4 \%)$, and self-identified as gay $(95 / 179,53 \%)$. Approximately one-third of the participants earned PHP 30,000 or more a year $(60 / 179$, $33.5 \%)$ and were between ages 25 and 29 years $(59 / 179,33.9 \%)$. Most had never experienced homelessness (158/179, 88.3\%) and had not recently been involved in sex work (153/179, $85.5 \%)$, but most were currently unemployed (133/179, 74.3\%). In addition, approximately half of the participants displayed high social cohesion $(97 / 179,54.2 \%)$, showed high general social participation $(87 / 179,48.6 \%)$, exhibited low LGBT-specific social participation $(109 / 179,60.9 \%)$, and reported poor or fair health care accessibility $(93 / 179,52 \%)$.

Half of the participants reported having no current health insurance $(88 / 179,49.2 \%)$, and $14.5 \%(26 / 179)$ reported having experienced health care discrimination because of their sexual identity. For HIV indicators, most of the participants had taken an HIV test $(142 / 179,79.3 \%)$, and less than half had avoided HIV services because of the cost of services $(72 / 179,40.2 \%)$, distance of travel to and from the health care facility $(72 / 179$, $40.2 \%)$, sexual identity $(50 / 179,27.9 \%)$, and lack of LGBT antidiscrimination policy $(36 / 179,20.1 \%)$. Over half of the participants demonstrated having high HIV knowledge (101/179, $56.4 \%)$.

Most of the participants were aware of PrEP (134/179, 74.9\%) and were interested in taking PrEP (159/179, 88.8\%), and approximately half discussed PrEP among friends (76/179, 42.5\%). In total, $11.7 \%$ (20/179) of Filipino cis-MSM indicated that they were not interested in taking PrEP and provided their primary reasons for not being interested. Of this subsample, the most common reasons for not being interested in PrEP were the need to know more information before taking PrEP (5/20, 25\%) and don't like taking pills (5/20, 25\%).

\section{Bivariable Logistic Regression Findings}

Findings from bivariable logistic regression on the correlates of PrEP awareness are presented in Multimedia Appendix 1.

Factors that were associated with greater odds of PrEP awareness included ( $P<.05$ in all instances) the following: having attained college education or higher versus high school education or lower (odds ratio [OR] 2.67, 95\% CI 1.05-6.77), having high LGBT-specific social participation (OR 3.34, 95\% CI 1.49-7.48), having had an HIV test (OR 5.50, 95\% CI 2.53-11.98), having high HIV knowledge (OR 2.76, 95\% CI 1.37-5.55), and having discussed PrEP among friends (OR 9.01, 95\% CI 3.35-24.25).
Factors that were associated with lower odds of PrEP awareness included $(P<.05$ in all instances $)$ the following: being straight-identified (OR 0.20, 95\% CI 0.05-0.75) and having experienced health care discrimination because of sexual identity (OR 0.21, 95\% CI 0.04-0.94). In addition, avoiding HIV services because of cost (OR $0.38,95 \%$ CI $0.19-0.76$ ), sexual identity (OR 0.47, 95\% CI 0.22-0.96), and lack of LGBT antidiscrimination policy (OR 0.43 , 95\% CI 0.19-0.94) were all associated with lower odds of PrEP awareness.

\section{Multivariable Logistic Regression Findings}

The findings from the multivariable logistic regression model are presented in Multimedia Appendix 1. Significantly greater odds of PrEP awareness were found among Filipino cis-MSM who had attained college education or higher versus high school education or lower (adjusted OR [aOR] 7.30, 95\% CI 1.01-52.47) and earned between PHP 10,000 and PHP 20,000 versus < PHP 10,000 (aOR 9.32, 95\% CI 1.41-6.22). Having ever had an HIV test was associated with approximately 6 times the odds of PrEP awareness (aOR 6.06, 95\% CI 1.20-13.55) compared with not having had an HIV test. Those who displayed high HIV knowledge had more than 3 times the odds of being aware of PrEP compared with those with low HIV knowledge (aOR 3.50, 95\% CI 1.11-10.98). Filipino cis-MSM who discussed PrEP among friends had greater odds of PrEP awareness (aOR 11.17, 95\% CI 2.73-14.50) compared with those who did not.

Significantly lower odds of PrEP awareness were associated with age and location. Specifically, participants aged 25-29 years (aOR $0.15,95 \%$ CI 0.02-0.90) and $\geq 35$ years (aOR 0.11 , 95\% CI 0.01-0.84) had lower PrEP awareness compared with 18- to 24-year-old participants. Participants living in Cebu had lower odds of PrEP awareness (aOR 0.83, 95\% CI 10.70-0.98) compared with those living in Metro Manila or NCR region.

\section{Discussion}

\section{Overview}

This paper offers insights on the potential of PrEP as an HIV prevention strategy among cis-MSM in the Philippines, a country with one of the fastest growing HIV crises in the world. Currently, the Philippines does not have an established PrEP program and is still in the nascent stages of rollout with only 1 current PrEP demonstration project. This follows broader trends in Asia, where few countries have implemented PrEP programs [33]. Insights in this paper point to a growing need and demand for PrEP in the Philippines for populations highly impacted by HIV, such as cis-MSM populations. The potential for the rollout of PrEP-based interventions and programming is contingent on 
public health efforts to increase levels of PrEP awareness of and interest in taking PrEP among cis-MSM in the Philippines.

Overall, PrEP awareness and interest in taking PrEP were high in our sample, as most participants indicated that they were both aware of and interested in PrEP. There have been few efforts to document PrEP awareness and interest across the Asia-Pacific region; what little research exists suggests that knowledge about PrEP is low in the region [33]. Our findings, however, contradict such research, as we found that most participants were aware of PrEP and had a high degree of PrEP knowledge. These results may have been because of our use of community-based organizations, which had HIV-specific programming and content, for recruitment. Moreover, previous research has found associations between high HIV knowledge and having access to and better engagement with HIV services [34,35]. In our sample, HIV knowledge was associated with greater odds of PrEP awareness. As such, it is plausible that Filipino cis-MSM may gain HIV knowledge and awareness of PrEP through their connections to HIV prevention services. However, further research is needed to elucidate this connection. Ultimately, this points to a potential role for community-based organizations in generating demand for and education on PrEP, a role that organizations in other settings have been willing and able to take.[36]. Indeed, Republica Act 11166, the new HIV policy recently passed in the Philippines, explicitly calls out the need for policy makers, practitioners, and scientists to work alongside such organizations in building a stronger HIV response [37]. Given these findings, a key policy step in building PrEP rollout in the Philippines could be the integration of community-based organizations as partners in the strategic planning and implementation processes from the very start of the national PrEP program.

The results from our multivariable model also imply the means by which PrEP implementation may be optimized. First, the association between having ever had an HIV test and awareness of PrEP is positive, as it demonstrates the potential linkage of PrEP education with routine health care, such as HIV tests. Prior research has argued that this routinization of PrEP discussions in the provision of other health services both destigmatizes PrEP and facilitates broader PrEP awareness [38]. As the Philippines continues to design the implementation of its own PrEP program, the integration of the burgeoning PrEP program alongside the continued expansion of HIV testing and service provision could yield the strongest uptake.

Second, the finding that discussion of PrEP with friends was linked to greater awareness of PrEP points to how social networks may be leveraged to improve PrEP uptake. Prior research has noted that social networks may play a role in promoting PrEP awareness [39]. However, research has also shown that MSM social networks may be a source of PrEP stigma - namely that PrEP is associated with sexual promiscuity and sexually transmitted infections [40]. Such stigma may serve as a barrier to PrEP education and use [41]. Although we did not specifically assess the nature of the discussions about PrEP in this study, future research should aim to do so to gauge the feasibility of using extended networks of cis-MSM to spread PrEP awareness and increase demand and use. Questions about the directionality of how knowledge is passed on (eg, whether having awareness of PrEP may lead to more discussion among friends about PrEP or whether having friends who discuss PrEP may lead to increased awareness of PrEP) and how individuals seek information about PrEP among friends who are also informed about PrEP within their social circles remain unanswered. Qualitative research may be especially useful in exploring this, as it may allow for a deeper understanding of the complex dynamics of social interaction around PrEP. Such research may shed light on how discussing PrEP with friends impacts awareness and desire to use PrEP.

Finally, it is worth noting the other correlates of PrEP awareness levels that we found. PrEP awareness in this sample was significantly lower among those over the age of 25 years (compared with those who were younger), who had very low income and education levels (compared with those with moderate to high income or education), and who resided in Cebu (compared with Manila). These results suggest that there are distinct health disparities across regions and socioeconomic strata within the population of cis-MSM in the Philippines. In addition to sociodemographics, it is important for future research in this area to better understand the sexual behaviors and relationship contexts (eg, casual vs romantic, long-term vs short-term, and monogamous vs having more than one partner) of cis-MSM who are unaware of PrEP, as PrEP may likely be beneficial to them and their partners. Such research can better inform PrEP campaigns aimed at promoting equity across cis-MSM populations. As such, there is a need for continually monitoring the reach of PrEP education and communication campaigns to mitigate such disparities within the country. Informational campaigns must particularly acknowledge differences in language or dialect, region, and literacy levels as potential barriers to PrEP awareness.

\section{Principal Findings}

Filipino cis-MSM are aware of and interested in taking PrEP. Those who were less aware of PrEP tended to come from poorer backgrounds and have less education. In addition, those who had encountered barriers to health care (ie, costs of medical visits or discrimination from health care staff) were less likely to be aware of PrEP. Incorporating PrEP education into routine HIV screening and leveraging cis-MSM social networks may be useful in increasing PrEP awareness and uptake.

\section{Limitations}

This study has several limitations worth noting. First, as we relied on sampling through community-based organizations, our sample is unlikely to be representative of the cis-MSM populations and therefore, our findings cannot be generalized to all cis-MSM in the Philippines, particularly those who may be at higher risk for HIV. That is, although all enrolled participants reported condomless anal sex in the past year, our participants come from 2 urban areas and most of them were educated (ie, approximately 121/179, 67.6\% had completed college education or above and 34/179, $19 \%$ had some college education) and therefore, may be more aware of HIV than those who do not have access to community-based organizations that offer HIV-related programs. As such, our findings may not accurately reflect the population of high-risk cis-MSM. This is underscored by the high level of HIV knowledge in our sample. 
Second, we recruited participants from major metropolitan areas in the Philippines, so our findings likely do not capture awareness and education in other regions (eg, rural areas). Finally, our survey was only offered in English; although English is a national language of the Philippines, those only comfortable communicating in Tagalog (or other dialects in the Philippines) were screened out. These individuals may differ significantly from our study sample (eg, comfort communicating only in Tagalog may reflect lower access to education) in ways that may have impacted our results.

\section{Conclusions}

Our research represents the first effort to characterize PrEP awareness and willingness to take PrEP among a sample of
Filipino cis-MSM. Our findings demonstrate that Filipino cis-MSM are aware of and interested in taking PrEP, but there is currently an unmet need for such biomedical HIV prevention technologies among this population. However, it must also be acknowledged that participants in our sample were likely to be engaged with HIV prevention services. More work is needed to identify the needs of less visible Filipino cis-MSM (ie, those disconnected from HIV prevention services who may be underserved by the national health care system of the Philippines). This study contributes to the scant research on this population and offers insights on the potential of PrEP as a means to reduce HIV among this population.

\section{Acknowledgments}

The authors would like to thank the health care providers who participated in this study. Their appreciation goes out to members of the study team: Patricia Rodarte, Savannah Gomes, Bianca Obiakor, and Valerie Santos. This work was supported by the Fogarty International Center of the National Institutes of Health (NIH) under grant D43TW010565, the National Institute on Drug Abuse of the NIH under grant R36DA048682, the Providence and Boston Center for AIDS Research under grant P30AI042853, the National Institute of Allergy and Infectious Diseases under grant T32AI102623, and the National Institute on Minority Health and Health Disparities of the NIH under grant 5T37MD008655 at the Brown University Global Health Initiative. AR is a recipient of the Robert Wood Johnson Foundation Health Policy Research Scholars and a Public Policy Fellow at amfAR, the Foundation for AIDS Research. The views and opinions expressed in this paper are solely those of the authors and do not necessarily represent the official views of the sponsors. The Fogarty International Center, National Institute on Drug Abuse, Providence and Boston Center for AIDS Research, National Institute of Allergy and Infectious Diseases, National Institute on Minority Health and Health Disparities, Robert Wood Johnson Foundation, and amfAR had no role in the design of the study; in the collection, analysis, and interpretation of the data; or in writing the manuscript.

\section{Authors' Contributions}

$\mathrm{AR}, \mathrm{AS}, \mathrm{AA}, \mathrm{WC}, \mathrm{AO}, \mathrm{HJ}$, and $\mathrm{AE}$ analyzed and interpreted the data regarding pre-exposure prophylaxis awareness. AR, AS, $\mathrm{AA}, \mathrm{WC}, \mathrm{AO}, \mathrm{HJ}$, and AE prepared the manuscript and were major contributors in writing the manuscript. AR, LH, SCU, and DO designed the study and were major contributors in writing, reviewing, and editing the manuscript. All authors read and approved the final manuscript.

\section{Conflicts of Interest}

None declared.

\section{Multimedia Appendix 1}

Bivariable and multivariable logistic regression models. [DOCX File, 22 KB-Multimedia Appendix 1]

\section{References}

1. Beyrer C, Sullivan P, Sanchez J, Baral SD, Collins C, Wirtz AL, et al. The increase in global HIV epidemics in MSM. AIDS 2013 Nov 13;27(17):2665-2678. [doi: 10.1097/01.aids.0000432449.30239.fe] [Medline: 23842129]

2. Beyrer C, Baral SD, van Griensven F, Goodreau SM, Chariyalertsak S, Wirtz AL, et al. Global epidemiology of HIV infection in men who have sex with men. Lancet 2012 Jul 28;380(9839):367-377 [FREE Full text] [doi: 10.1016/S0140-6736(12)60821-6] [Medline: 22819660]

3. Nygren-Krug H. The Joint United Nations Programme on HIV/AIDS. In: Human Rights in Global Health: Rights-Based Governance for a Globalizing World. Oxford, UK: Oxford Scholarship Online; 2018.

4. Department of Health Epidemiology Bureau. 2019. URL: https://doh.gov.ph/sites/default/files/statistics/ EB HARP September AIDSreg2019.pdf [accessed 2021-11-17]

5. Ross AG, Ditangco RA, Belimac JG, Olveda RM, Mercado ES, Rogers GD, et al. HIV epidemic in men who have sex with men in Philippines. Lancet Infect Dis 2013 Jun;13(6):472-473. [doi: 10.1016/S1473-3099(13)70129-4] [Medline: 23718916]

6. Gangcuangco LM, Tan ML, Berba RP. Prevalence and risk factors for HIV infection among men having sex with men in Metro Manila, Philippines. Southeast Asian J Trop Med Public Health 2013 Sep;44(5):810-817. [Medline: 24437316] 
7. Toleran DE, Friese B, Battle RS, Gardiner P, Tran PD, Lam J, et al. Correlates of HIV and HCV risk and testing among Chinese, Filipino, and Vietnamese men who have sex with men and other at-risk men. AIDS Educ Prev 2013 Jun;25(3):244-254. [doi: 10.1521/aeap.2013.25.3.244] [Medline: 23631718]

8. Consolidated Guidelines on HIV Prevention, Diagnosis, Treatment and Care for Key Populations. Geneva: World Health Organization; 2014.

9. Grant RM, Lama JR, Anderson PL, McMahan V, Liu AY, Vargas L, iPrEx Study Team. Preexposure chemoprophylaxis for HIV prevention in men who have sex with men. N Engl J Med 2010 Dec 30;363(27):2587-2599 [FREE Full text] [doi: 10.1056/NEJMoa1011205] [Medline: 21091279]

10. Choopanya K, Martin M, Suntharasamai P, Sangkum U, Mock PA, Leethochawalit M, Bangkok Tenofovir Study Group. Antiretroviral prophylaxis for HIV infection in injecting drug users in Bangkok, Thailand (the Bangkok Tenofovir Study): a randomised, double-blind, placebo-controlled phase 3 trial. Lancet 2013 Jun 15;381(9883):2083-2090. [doi:

10.1016/S0140-6736(13)61127-7] [Medline: 23769234]

11. Philippines. PrEPWatch. URL: https://www.prepwatch.org/country/philippines/) [accessed 2021-11-17]

12. Kelley CF, Kahle E, Siegler A, Sanchez T, Del Rio C, Sullivan PS, et al. Applying a PrEP continuum of care for men who have sex with men in Atlanta, Georgia. Clin Infect Dis 2015 Nov 15;61(10):1590-1597 [FREE Full text] [doi: 10.1093/cid/civ664] [Medline: 26270691]

13. Nunn A, Brinkley-Rubinstein L, Oldenburg CE, Mayer KH, Mimiaga M, Patel R, et al. Defining the HIV pre-exposure prophylaxis care continuum. AIDS 2017 Mar 13;31(5):731-734 [FREE Full text] [doi: 10.1097/QAD.0000000000001385] [Medline: 28060019]

14. Goedel WC, Halkitis PN, Greene RE, Duncan DT. Correlates of awareness of and willingness to use Pre-exposure Prophylaxis (PrEP) in gay, bisexual, and other men who have sex with men who use geosocial-networking smartphone applications in New York City. AIDS Behav 2016 Jul;20(7):1435-1442. [doi: 10.1007/s10461-016-1353-6] [Medline: 26966013]

15. Bauermeister J, Meanley S, Pingel E, Soler J, Harper G. PrEP awareness and perceived barriers among single young men who have sex with men. Curr HIV Res 2013 Oct;11(7):520-527 [FREE Full text] [doi: 10.2174/1570162x12666140129100411] [Medline: 24476355]

16. Yi S, Tuot S, Mwai GW, Ngin C, Chhim K, Pal K, et al. Awareness and willingness to use HIV pre-exposure prophylaxis among men who have sex with men in low- and middle-income countries: a systematic review and meta-analysis. J Int AIDS Soc 2017 Jun 26;20(1):21580 [FREE Full text] [doi: 10.7448/IAS.20.1.21580] [Medline: 28691439]

17. Restar A, Nguyen M, Nguyen K, Adia A, Nazareno J, Yoshioka E, et al. Trends and emerging directions in HIV risk and prevention research in the Philippines: a systematic review of the literature. PLoS One 2018 Dec 5;13(12):e0207663 [FREE Full text] [doi: 10.1371/journal.pone.0207663] [Medline: 30517178]

18. Gonzalez A. The language planning situation in the Philippines. J Multilingual Multicultural Develop 1998 Sep;19(5):487-525. [doi: 10.1080/01434639808666365]

19. Kincaid J, Fishburne RP, Rogers RL, Chissom BS. Derivation Of New Readability Formulas (Automated Readability Index, Fog Count And Flesch Reading Ease Formula) For Navy Enlisted Personnel. Orlando: Institute for Simulation and Training, University of Central Florida; 1975.

20. Umbach PD. Web surveys: best practices. New Directions Institutional Res 2004;2004(121):23-38. [doi: 10.1002/ir.98]

21. Van Selm M, Jankowski NW. Conducting online surveys. Qual Quant 2006 Jun;40(3):435-456. [doi: 10.1007/s11135-005-8081-8]

22. King DB, O'Rourke N, DeLongis A. Social media recruitment and online data collection: a beginner's guide and best practices for accessing low-prevalence and hard-to-reach populations. Canadian Psychology/Psychologie canadienne 2014;55(4):240-249. [doi: $10.1037 / \mathrm{a} 0038087$ ]

23. National Demographic and Health Survey 2017. The World Bank. 2018. URL: https://microdata.worldbank.org/index.php/ catalog/3220 [accessed 2021-11-17]

24. Lippman SA, Donini A, Díaz J, Chinaglia M, Reingold A, Kerrigan D. Social-environmental factors and protective sexual behavior among sex workers: the Encontros intervention in Brazil. Am J Public Health 2010 Apr 01;100 Suppl 1:S216-S223 [FREE Full text] [doi: 10.2105/AJPH.2008.147462] [Medline: 19762673]

25. Fonner VA, Kerrigan D, Mnisi Z, Ketende S, Kennedy CE, Baral S. Social cohesion, social participation, and HIV related risk among female sex workers in Swaziland. PLoS One 2014 Jan 31;9(1):e87527 [FREE Full text] [doi: 10.1371/journal.pone.0087527] [Medline: 24498125]

26. Grover E, Grosso A, Ketende S, Kennedy C, Fonner V, Adams D, et al. Social cohesion, social participation and HIV testing among men who have sex with men in Swaziland. AIDS Care 2016;28(6):795-804. [doi: 10.1080/09540121.2015.1131971] [Medline: 26824888]

27. Haggerty J, Lévesque JF, Santor D, Burge F, Beaulieu C, Bouharaoui F, et al. Accessibility from the patient perspective: comparison of primary healthcare evaluation instruments. Healthc Policy 2011 Dec;7(Spec Issue):94-107 [FREE Full text] [Medline: 23205038]

28. Davis C, Sloan M, Macmaster S, Hughes L. The International AIDS Questionnaire—English Version (IAQ-E). J HIV/AIDS Prevent Child Youth 2007 May 15;7(2):29-42. [doi: 10.1300/j499v07n02_03] 
29. Restar AJ, Kuhns L, Reisner SL, Ogunbajo A, Garofalo R, Mimiaga MJ. Acceptability of antiretroviral pre-exposure prophylaxis from a cohort of sexually experienced young transgender women in two U.S. Cities. AIDS Behav 2018 Nov;22(11):3649-3657 [FREE Full text] [doi: 10.1007/s10461-018-2127-0] [Medline: 29713838]

30. Garofalo R, Johnson AK, Kuhns LM, Cotten C, Joseph H, Margolis A. Life skills: evaluation of a theory-driven behavioral HIV prevention intervention for young transgender women. J Urban Health 2012 Jun;89(3):419-431 [FREE Full text] [doi: 10.1007/s11524-011-9638-6] [Medline: 22223033]

31. O'brien RM. A caution regarding rules of thumb for variance inflation factors. Qual Quant 2007 Mar 13;41(5):673-690. [doi: $10.1007 / \mathrm{s} 11135-006-9018-6]$

32. Statacorp Stata MP 15.1 free download full version for windows. StataCorp. URL: https://www.getintopces.com/ statacorp-stata-mp-15-1-free-download/ [accessed 2021-11-17]

33. Zablotska I, Grulich AE, Phanuphak N, Anand T, Janyam S, Poonkasetwattana M, et al. PrEP implementation in the Asia-Pacific region: opportunities, implementation and barriers. J Int AIDS Soc 2016 Oct 18;19(7(Suppl 6)):21119 [FREE Full text] [doi: 10.7448/IAS.19.7.21119] [Medline: 27760688]

34. Hatcher AM, Turan JM, Leslie HH, Kanya LW, Kwena Z, Johnson MO, et al. Predictors of linkage to care following community-based HIV counseling and testing in rural Kenya. AIDS Behav 2012 Jul;16(5):1295-1307 [FREE Full text] [doi: 10.1007/s10461-011-0065-1] [Medline: 22020756]

35. Jones D, Cook R, Rodriguez A, Waldrop-Valverde D. Personal HIV knowledge, appointment adherence and HIV outcomes. AIDS Behav 2013 Jan;17(1):242-249 [FREE Full text] [doi: 10.1007/s10461-012-0367-y] [Medline: 23143751]

36. Smith DK, Maier E, Betts J, Gray S, Kolodziejski B, Hoover KW. What community-based HIV prevention organizations say about their role in biomedical HIV prevention. AIDS Educ Prev 2016 Oct;28(5):426-439. [doi: 10.1521/aeap.2016.28.5.426] [Medline: 27710082]

37. Adia AC, Restar AJ, Lee CJ, Payawal MP, Quilantang MI, Nazareno J, et al. Sword and Shield: perceptions of law in empowering and protecting HIV-positive men who have sex with men in Manila, Philippines. Glob Public Health 2020 Jan;15(1):52-63. [doi: 10.1080/17441692.2019.1622762] [Medline: 31134838]

38. Calabrese SK, Krakower DS, Mayer KH. Integrating HIV Preexposure Prophylaxis (PrEP) into routine preventive health care to avoid exacerbating disparities. Am J Public Health 2017 Dec;107(12):1883-1889. [doi: 10.2105/ajph.2017.304061] [Medline: 29048955]

39. Khanna AS, Schumm P, Schneider JA. Facebook network structure and awareness of preexposure prophylaxis among young men who have sex with men. Ann Epidemiol 2017 Mar;27(3):176-180 [FREE Full text] [doi:

10.1016/j.annepidem.2016.11.006] [Medline: 28003117]

40. Dubov A, Galbo P, Altice FL, Fraenkel L. Stigma and shame experiences by MSM who take PrEP for HIV prevention: a qualitative study. Am J Mens Health 2018 Nov;12(6):1843-1854 [FREE Full text] [doi: 10.1177/1557988318797437] [Medline: 30160195]

41. Eaton LA, Kalichman SC, Price D, Finneran S, Allen A, Maksut J. Stigma and conspiracy beliefs related to Pre-exposure Prophylaxis (PrEP) and interest in using PrEP among Black and White men and transgender women who have sex with men. AIDS Behav 2017 May;21(5):1236-1246 [FREE Full text] [doi: 10.1007/s10461-017-1690-0] [Medline: 28108878]
Abbreviations
aOR: adjusted odds ratio
cis-MSM: cisgender men who have sex with men
LGBT: lesbian, gay, bisexual, and transgender
NCR: National Capital Region
NIH: National Institutes of Health
OR: odds ratio
PrEP: pre-exposure prophylaxis

Edited by $R$ Kukafka; submitted 09.09.20; peer-reviewed by P Seekaew, T Winder; comments to author 11.10.20; revised version
received 14.10.20; accepted 23.09.21; published 07.01.22
Please cite as:
Restar A, Surace A, Adia A, Goedel W, Ogunbajo A, Jin H, Edeza A, Hernandez L, Cu-Uvin S, Operario D
Characterizing Awareness of Pre-Exposure Prophylaxis for HIV Prevention in Manila and Cebu, Philippines: Web-Based Survey of
Filipino Cisgender Men Who Have Sex With Men
J Med Internet Res 2022;24(1):e24126
URL: $\underline{\text { https://www.jmir.org/2022/1/e24126 }}$
doi: $10.2196 / 24126$
PMID:


(C)Arjee Restar, Anthony Surace, Alexander Adia, William Goedel, Adedotun Ogunbajo, Harry Jin, Alberto Edeza, Laufred Hernandez, Susan Cu-Uvin, Don Operario. Originally published in the Journal of Medical Internet Research (https://www.jmir.org), 07.01.2022. This is an open-access article distributed under the terms of the Creative Commons Attribution License (https://creativecommons.org/licenses/by/4.0/), which permits unrestricted use, distribution, and reproduction in any medium, provided the original work, first published in the Journal of Medical Internet Research, is properly cited. The complete bibliographic information, a link to the original publication on https://www.jmir.org/, as well as this copyright and license information must be included. 